\title{
TRAS SER DESFIGURADO, FRANCISCO DE ROJAS ZORRILLA ENTRA EN EL PARNASO ESPAÑOL. LOS SIGLOS XVIII Y XIX
}

\author{
JOAQUín ÁLVAREZ BARRIENTOS
}

Instituto de la Lengua Española, CSIC

\section{RESUMEN}

El artículo estudia la presencia del teatro de Francisco de Rojas en los escenarios españoles de los siglos XVIII y XIX, así como el modo en que los críticos e historiadores de la literatura valoraron a ese autor. Se detallan las refundiciones de sus obras, su relación con Fernández de Moratín y su entrada en el Parnaso nacional.

Palabras clave: Rojas. Refundición. Canon. Cartelera. Historiografía.

\section{ABSTRACT}

The article studies the presence of the theater of Francisco de Rojas in the Spanish scenes of centuries XVIII and XIX, as well as the way in which the critical and historians of Literature valued that author. The refundiciones of their works, their relation with Fernandez de Moratín and their entrance in the national Parnaso are detailed.

Key words: Rojas. Refundiciones. Canon. Billboard. Historiography.

Francisco de Rojas Zorrilla es uno de los nombres más frecuentes en los escritos teatrales de los siglos XVIII y XIX y, desde luego, en la cartelera. Su presencia en ésta puede oscilar, pero siempre es constante, a diferencia de lo que sucede con otros dramaturgos del Siglo de Oro. Del mismo modo, al hilo de sus éxitos en la escena, recibe la atención de los impresores y se editan sus comedias, sueltas, al igual que algunos monólogos de las mismas en pliegos de cordel y relaciones.

Rojas Zorrilla participó, como elemento paciente, en las polémicas sobre la condición y sentido del teatro clásico español, y fue uno de los que dio continuidad a la historia dramática y a una forma de representar y entender el teatro «español» por esa continuada presencia en los escenarios. Ramón de Mesonero Romanos, que lo editó en 1861 dentro de la Biblioteca de Autores Españoles, lo introdujo definitivamente en el Parnaso nacional, aunque antes hubo otros momentos gloriosos para este autor, como la edición de sus Comedias escogidas de 1827, su inclusión en el Theatro Hespañol, la antología de Vicente García de la Huerta, y otros que se detallarán. 
Por otro lado, conoció cierta dimensión europea, ya mediante traducción, o directamente apropiación de sus ficciones, como otros grandes escritores españoles del Siglo de Oro. Entre bobos anda el juego fue titulada por Thomas Corneille Don Beltrán del Cigarral; Scarron llamó a Donde hay agravios no hay celos, Jodelet maître et valet; el Wenceslao de Rotrou es imitación de No hay ser padre siendo rey; y Lesage incorporó a su novela Gil Blas la comedia Casarse por vengarse.

Rojas, por tanto, junto a Lope, Calderón, Tirso, Ruiz de Alarcón y Moreto, es uno de los importantes a la hora de crear el canon del teatro barroco, como corroboró Mesonero Romanos en la introducción a su selección de comedias escogidas para la Biblioteca de Autores Españoles: «Llega, por fin, don Francisco de Rojas a ocupar el lugar que le corresponde en esta Colección de nuestros insignes dramáticos del siglo XVII, la más copiosa, metódica y selecta que hasta ahora se formó dentro y fuera de España de aquel inapreciable tesoro». Esta colección la formaban dieciséis volúmenes de la Biblioteca, e incorporaban selecciones de los arriba citados, a cargo de especialistas como Hartzenbusch (Lope, Tirso, Alarcón y Calderón), Luis Fernández- Guerra (Moreto), y el mismo Mesonero, que se hizo cargo de Rojas y de los dramaturgos contemporáneos y posteriores a Lope ${ }^{1}$.

\section{CARTELERA Y REFUNDICIÓN: ROJAS DESFIGURADO}

La presencia de Rojas en las tablas queda atestiguada en las diferentes carteleras que se han publicado ${ }^{2}$. Algunas de sus comedias tuvieron poco éxito, como Lo que quería ver el marqués de Villena, que se vio solo en el Teatro de la Cruz de Madrid el 31 de enero de 1710, pero su nombre y sus piezas atraviesen la centuria, repuestas numerosas veces. Es el caso de la tan famosa Entre bobos anda el juego y todos eran fulleros, don Lucas

${ }^{1}$ Comedias escogidas de don Francisco de Rojas Zorrilla, BAE 54, p. V. Rojas es «uno de nuestros seis grandes dramáticos que la crítica moderna ha clasificado en el primer orden» (p. VI). La mayor aportación posterior al conocimiento de este autor se debe a Emilio Cotarelo y MoRI, Don Francisco de Rojas Zorrilla. Noticias biográficas y bibliográficas, Madrid, Impr. De la Revista de Archivos, 1911. Véanse también los trabajos de Raymond R. MacCurdy.

${ }^{2}$ René ANDIOC y Mireille Coulon, Cartelera teatral madrileña del siglo XVIII (17081808), Toulouse, Presses Universitaires du Miral, 1996, 2 vols., y Josep M. ${ }^{\text {a }}$ SALA VALlDAURA, El teatro en Barcelona entre la Ilustración y el Romanticismo: o las musas de guardilla, Lérida, Ed. Milenio, 2000. Véase también Ada M. CoE, Catálogo bibliográfico y crítico de las comedias anunciadas en los periódicos de Madrid desde 1661 hasta 1819, Paris, Les Belles Lettres, 1935; Cartelera teatral madrileña, I: 1830-1839, Madrid, CSIC, 1961 (y II: 1840-1849), Madrid, CSIC, 1963; Archibald K SHIELDS, The Madrid Stage 1820-1830, Chapel Hill, University of North Carolina, 1933, y Piero MENARINI, El teatro romántico español (1830-1850). Autores, obras, bibliografía, Bolonia, ATESA, 1982. 
del Cigarral, que inicia su singladura dieciochesca en Madrid en 1715. Ésta como otras del mismo autor formaba parte del repertorio de los cómicos y parece que se echa mano de ella cada vez que se necesita rellenar algún hueco en la programación. La cartelera de Andioc y Coulon revela que cada vez que se repone, solo dura un día. Y lo mismo sucede con su otra comedia emblemática, Del rey abajo ninguno, y labrador más honrado García del Castañar, que desde 1710 hasta 1807 pudo verse ininterrumpidamente, pero solo un día cada vez, aunque algunos años se reestrena en dos ocasiones, lo mismo que Los áspides de Cleopatra, repuesta desde 1709, y Los bandos de Verona, Montescos y Capeletes, reestrenada entre 1709 y 1797. Progne y Filomena tuvo una vida escénica más corta, pues parece que después de 1776 no volvió a representarse. De nuevo, cada ocasión que se repuso, duró un solo día, con el agravante de que, siguiendo la tónica habitual, no se señalaba el nombre del autor en el anuncio, lo que no permite saber si la Progne y Filomena que se vio fue la suya o la de Guillén de Castro, o las de ambos según los días. En todo caso, quizá fuera la suya y el trabajo de refundición de Sebastián y Latre, al que se alude a continuación, consiguiera su propósito de sacarla de los circuitos escénicos.

Esta obra de Rojas Zorrilla nos enfrenta ante una práctica literaria que, aunque estuvo presente en épocas anteriores, en realidad tuvo sus orígenes en el siglo XVIII. Me refiero al problema de las refundiciones. Mucho del teatro clásico que se vio en la segunda mitad del XVIII y en parte del XIX era teatro refundido que, en ocasiones, nada se parecía a la obra original. El caso quizá más conocido fue el de La vida es sueño, que desde el principio resultaba ser otra obra. El monólogo famoso del «Hipógrifo violento» era sustituido por este diálogo «Dentro» mientras empezaba a oscurecer, en lugar de amanecer, como figura en el original:

$\begin{array}{ll}\text { ROSAURA: } & \text { ¡Ay infeliz! } \\ \text { ClARÍN: } & \text { Mira que desbocado } \\ & \text { El indómito bruto baja al Prado } \\ & \text { Y antes que él baje, medirás el suelo } \\ & \text { Si no te agarras bien. } \\ \text { ROSAURA: } & \text { ¡Valedme cielos! } \\ \text { CLARÍN: } & \text { Dicho y hecho: fortuna que soltaste } \\ & \text { El estribo y al brinco te arrojaste }\end{array}$

Progne y Filomena fue refundida en 1772 por Tomás Sebastián y Latre, junto con El parecido en la corte de Moreto, en Ensayo sobre el teatro español ${ }^{4}$. Cañizares había adaptado comedias de Lope y en el siglo XVII

${ }^{3}$ Ermanno CALDERA, «Calderón desfigurado. Sobre las representaciones calderonianas en la época prerromántica», Anales de Literatura Española, 2 (1983), pp. 57-81. El otro monólogo famoso, de Segismundo (II, 19), no variaba salvo al final: «toda la vida es sueño/ y los sueños nada son».

${ }^{4}$ Zaragoza, Imprenta del Rey, 1772. Se reeditó en Madrid al año siguiente. 
había sido frecuente rehacer obras de ingenios anteriores, pero la diferencia entre esos trabajos y las refundiciones que comienzan con Sebastián y Latre y con el conde de Aranda y Bernardo de Iriarte son otra cosa y tienen mayor calado estético e ideológico. El trabajo supone convertir a la comedia en un texto apto para el sentido clasicista del momento; de manera que, si se censuran «errores» estéticos y desaciertos expresivos, se corrige también el aspecto moral de la obra ${ }^{5}$. Mientras que en los autores anteriores había una similar o la misma manera de entender el mundo y la escena, en el caso de las refundiciones dieciochescas (y luego con las románticas) se enfrentan dos modos diferentes de concebir la realidad y la representación dramática ${ }^{6}$. Hasta tal punto llegó a ser importante esta labor de adaptación de la tradición dramática española que durante un tiempo fue «proyecto de Estado» dirigido por el conde de Aranda, y más tarde se reguló como trabajo literario que se pagaba de modo diferente a otras obras, breves, nuevas o con música ${ }^{7}$.

La refundición de comedias, además de tener una función ideológica y estética inmediata en el aspecto de la representación —es decir, como mediador de un mensaje nuevo y actual desde un molde antiguo-, cumplía con otro objetivo central de los ideólogos ilustrados: frente a los castizos

${ }^{5}$ Emilio PALACIOS FernáNDEZ, «El teatro barroco español en una carta de Bernardo de Iriarte al conde de Aranda (1767)», Cuadernos de Teatro Clásico, 5 (1990), pp. 43-64. De Rojas Zorrilla seleccionó Iriarte las siguientes: Abre el ojo, Entre bobos anda el juego, Casarse por vengarse, Sin honra no hay amistad, Lo que son mujeres, No hay amigo para amigo y Donde hay agravio no hay celos.

${ }^{6}$ Sobre refundiciones, puede verse Francisco AGUILAR PIÑAL, «Las refundiciones en el siglo XVIII», Cuadernos de Teatro Clásico, 5 (1990), pp. 33-41; Un escritor ilustrado: Cándido María Trigueros, Madrid, CSIC, 1987; Javier Vellón LAHOZ, «El proceso de refundición como práctica ideológica: La dama duende de Juan José Fernández Guerra», Cuadernos de Teatro Clásico, 5 (1990), pp. 99-109; «Tirso desde la perspectiva neoclásica: La villana de Vallecas de Dionisio Solís», Estudios, 184 (1994), pp. 532; Ermanno CALDERA, «I refundidores», en Il dramma romantico in Spagna, Pisa, Universitá, 1974; «Bretón o la negación del modelo», Cuadernos de Teatro Clásico, 5 (1990), pp. 141-153; David T. GIES, «Notas sobre Grimaldi y 'el furor de refundir' en Madrid (1820-1823)», Cuadernos de Teatro Clásico, 5 (1990), pp. 111-124; Charles GANELIN, Rewriting Theatre: The Comedia and Nineteenth-Century Refundición, Lewisburg, Bucknell University Press, 1994; Joaquín ÁlvareZ BARRIENTOS, «Revisando el teatro clásico español: La refundición de comedias en el siglo XIX», en Actas del I Congreso de Historia y Crítica del Teatro de Comedias, Ayto. del Puerto de Santa María, 1995, pp. 27-39. Hace falta un estudio general y actualizado sobre Dionisio Solís, seguramente el mayor refundidor de la época romántica. En los artículos recogidos en esta nota se encuentran referencias a él y a su escueta bibliografía. Véase también David T. GIES, El teatro en la España del siglo XIX, Cambridge, University Press, 1996 y M. ${ }^{a}$ José RodRíGuez SÁNCHEZ DE LEÓN, La crítica dramática en España (1789-1833), Madrid, CSIC, 1999.

${ }^{7}$ La refundición se reguló en el Reglamento general para la dirección y reforma de teatros de 1807; véase Emilio COTARELO Y MORI, Bibliografía de las controversias sobre la licitud del teatro en España, Madrid, Tipografía de la Revista, 1904. 
que se apropiaban del teatro clásico español y lo hacían pasar por lo auténtico nacional, haciendo suya esa parte de la historia cultural del país; ellos quisieron mostrar que también podía ser su patrimonio, el de aquellos «otros» españoles, si bien con las debidas «correcciones». Estas actuaciones formaban parte de la lucha por interpretar la historia y el pasado cultural de la nación ${ }^{8}$. Desde otro punto de vista, el refundidor se convertía en un intermediario entre la tradición y los nuevos modelos culturales, y eso es lo que hizo Sebastián y Latre con su versión de Progne y Filome$n a, \mathrm{y}$ antes Bernardo de Iriarte con su selección.

¿Por qué eligió Sebastián y Latre la tragedia de Rojas Zorrilla para ejemplificar las posibilidades y la utilidad de la refundición como estrategia de intermediación reformadora? ¿Le ofrecían el autor y su obra más posibilidades? Desde luego, unas obras eran más fáciles de adaptar que otras, como queda claro en las diferentes selecciones que se hicieron y en los comentarios de teóricos y refundidores. Sebastián y Latre fue cronista de Zaragoza y miembro de la Sociedad Aragonesa de Amigos del País. Lo que se conoce de su producción se reduce a una versificación de la traducción en prosa del Británico de Racine realizada por Juan Trigueros, a las adaptaciones de Rojas y Moreto, y a diversos escritos sobre la ciudad —uno de ellos realmente interesante sobre el motín de Esquilache-, relaciones festivas y celebrativas, y su memoria sobre el incendio del coliseo zaragozano en $1778^{9}$.

Su Ensayo del teatro español apareció en Zaragoza en 1772 y conoció una reimpresión al año siguiente en Madrid. Lo publica en un momento de reforma y debate sobre la función del teatro y dedicado al conde de Aranda que, por entonces, tenía competencias en la materia, como Presidente del Consejo de Castilla, que fue hasta $1773^{10}$. El oportunismo del Cronista no se puede poner en duda, sí quizá el momento, pues ofrece y publica el trabajo en los años finales de su mandato, cuando Bernardo de Iriarte llevaba trabajando en la adaptación de comedias y tragedias, por orden del

${ }^{8}$ He estudiado este asunto en «Pedro Calderón de la Barca en los siglos XVIII y XIX. Fragmentos para la historia de una apropiación», en Estado actual de los estudios calderonianos, ed. Luciano García Lorenzo, Kassel, Reichenberger, 2000, pp. 279-324; «Nación e historia literaria a mediados del siglo XVIII en España», en Historia literarial Historia de la literatura, ed. Leonardo Romero Tobar, Prensas Universitarias de Zaragoza, 2004, pp. 101-114; y «El Barroco en el debate dieciochesco sobre la identidad nacional», en Temas del Barroco Hispánico, eds. Ignacio Arellano y Eduardo Godoy, Pamplona, Universidad de Navarra/ Iberoamericana Vervuert, 2004, pp. 11-23.

9 Véase Francisco AgUILAR PIÑAL, Bibliografía de autores españoles del siglo XVIII, VII, Madrid, CSIC, 1993, pp. 617-619.

${ }^{10}$ Javier Vellón LAHOZ, «El Ensayo sobre el teatro español de Sebastián y Latre: la refundición del teatro barroco como instrumento ideológico», Dieciocho, 17.2 (1994), pp. 165-176; Jesús Rubio JimÉNEZ, El conde de Aranda y el teatro, Zaragoza, iberCaja, 1998. 
conde, desde los años sesenta, y en agosto de 1767 le había presentado ya su informe al respecto.

Las razones de Sebastián y Latre se encuadran en el marco de la reforma de la escena, como ya se señaló, pero también en un ámbito mayor relativo a la transformación de la sociedad española, pretende crear un nuevo individuo, un ciudadano católico, desde el teatro, cambiando sus costumbres y el referente de sus antiguos contenidos. Sebastián y Latre, como los demás refundidores, realiza una tarea patriótica, y pretende contribuir a la nueva España que había de salir de las leyes, de la historia y, por supuesto, del teatro, centro y fuente de toda educación popular. Pero, además, la tarea se dirige también a crear un nuevo concepto de patria y nación, desde la reinterpretación del pasado: una reinterpretación que, como la de los castizos, admite «correcciones» e idealismos. Los ilustrados miran hacia atrás críticamente y arreglan, restauran o refunden aquello susceptible de reconocerse en sus valores, que son universales y de futuro, pues creen en la perfectibilidad del individuo y de sus instituciones. Así, por ejemplo, es sintomática esta declaración de intenciones, a su vez motivadora del trabajo: tras señalar que su impulso es francés, pues estos han conseguido hacer buenas obras de nuestro teatro, se muestra nacionalista, pero de un modelo nuevo de español:

Me obligó a pensar con seria reflexión cuán debido era que nosotros prefiriésemos alguna vez los gritos del juicio y la razón a los de una multitud de gente obstinada en sostener que nuestras comedias son propias del carácter de la nación; y que por consiguiente sus duelos, lances, incidentes y aventuras nos son connaturales. Como si esto pudiera defenderse más que por un capricho ridículo y un punto de honor despreciable, creyendo que es amar a sus patriotas el defender sus yerros ${ }^{11}$.

A diferencia de los castizos y de los escritores de los años veinte y treinta, no piensa que el teatro del Barroco exprese la condición de los españoles. Por el contrario, es consciente de que está colaborando en un plan más amplio de re-construcción de una identidad nacional o histórica, en la que los espectadores puedan reconocerse, de la que hay que apartar toda una serie de defectos y errores. Pretende crear, como otros refundidores ilustrados, una nueva comunidad de sentido en la reinterpretación del pasado. La razón y la nueva sensibilidad ilustrada son las que dan las pautas éticas y estéticas de esa reconstrucción al nuevo espectador. Traza en su introducción las líneas maestras de su actuación apurando razonamientos que se repetían una y otra vez y que por entonces eran de uso corriente. Al mismo tiempo, en el reparto de culpas por el mal estado del teatro, no se pierde de vista al vulgo, pero un vulgo considerado como ya describió Feijoo: no sólo «la gente sencilla y sin instrucción», sino también un «vul-

${ }^{11}$ Ensayo sobre el teatro español, cit., s. p. 
go, al parecer culto o que debería serlo», que es quien se defiende de las novedades por rutina y porque no las entiende. Este grupo de poderosos son los que avalan el mal gusto y «illaman novedades a lo que es seguir las poéticas de Aristóteles y Horacio!».

Se apoya en Luzán, en Montiano y Luyando, en Nasarre, en Cascales, en Cervantes, Racine y Boileau; hace a Lope culpable de las irregularidades, y repite la serie de tópicos ya conocidos. Justifica su decisión de adaptar la comedia de Moreto y la tragedia de Rojas en función del dudoso mensaje que propagan al auditorio. La pieza de Rojas Zorrilla, en concreto, rompe el decoro constantemente y de todas las formas posibles: hay violencia, lascivia y sangre, lo cual no es presentable, pero además se mezcla lo serio de la tragedia con lo cómico, de manera que ni se respeta el orden de los géneros ni la importante unidad de tono, pues se quiebra el efecto de ilusión escénica, perseguido por los teóricos del teatro ${ }^{12}$.

Pero, la elección de la tragedia de Rojas Zorrilla tiene un elemento añadido importante de carácter político y cívico. En ella se da, con participación de la esposa, la muerte del rey tirano. Rojas atentaba de este modo contra dos instituciones esenciales para la dinastía borbónica, cuyas imágenes se querían adaptar a los tiempos. La monarquía y la familia. Son años en los que la propaganda ilustrada, desde el teatro, ofrece una idea del rey como padre, y en los que se está legislando el papel de padres e hijos en la elección de estado, pero también en los que la misma institución matrimonial está sometida a debate, con los cortejos y sus críticos, con los que están a favor y en contra del divorcio. Rojas hace que se asesine al rey y que su esposa esté de acuerdo, minando así las dos instituciones esenciales de la sociedad monárquica. Sebastián y Latre corrige estos mensajes, pues la escuela que es el teatro no debe difundirlos, y rehace el argumento para que el rey de Tracia, que en la comedia es asesinado por violar a Filomena, vuelva con su esposa, restaurando el valor de la monarquía y de la familia. La misma Progne es la que rechaza la venganza de su hermana

12 «No me estimuló a ello el ver quebrantadas cuantas reglas tiene la poesía dramática, en las unidades, en el carácter de las personas, en la ninguna conexión de la fábula ni en las bajezas y bufonadas indignas que en ella se advierten. Me obligaron a esto dos cosas: la una aquella bárbara y lasciva escena en que Filomena, después de haber padecido en su honor el mayor insulto y violencia se presenta a Hipólito y con ademanes y artificios (por haberla también cortado la lengua) le da noticia de la torpeza y crueldad que su hermano Tereo acababa de ejecutar con ella, preparando antes el lance de un modo que hace más perceptible y escandaloso el suceso. ¡Perniciosa enseñanza para jóvenes libres! ¡Y escandaloso espectáculo para doncellas incautas! He visto representar esta comedia algunas veces y en este paso no hay persona honesta ni juiciosa a quien no se le note el rubor, y sé de muchos timoratos que se abstienen de ir cuando se representa», Ensayo sobre el teatro español, cit., s. p. Sobre el debate preceptista, José CheCA Beltrán, Razones del buen gusto (Poética española del Neoclasicismo), Madrid, CSIC, 1998. 
Filomena y la mata ${ }^{13}$. Así, resumirá: «el motivo que tuve para elegir estos dos piezas fue el parecerme hacía un grande obsequio al público en procurar desterrarlas del teatro, especialmente la de Rojas». Su objetivo, por tanto, con «estas dos piezas [que] andan en las manos de todos y cada día se representan», es dar una lección de civismo, contribuir a la educación de la nación, dotar de nuevo sentido a ese teatro, reformar la vida pública ${ }^{14}$.

Como en otros casos, el referente del refundidor es el modelo francés. Los autores franceses, al adaptar las obras españolas, las habían «corregido» según su gusto clasicista y consiguieron mejores resultados. Es éste, por ejemplo, uno de los motivos de que algunos prefirieran el Quijote de Avellaneda al de Cervantes y es, en parte, la razón que adoptan Montiano y Nasarre para propiciar su edición en $1732^{15}$. Pero además, a la hora de entender mejor el fenómeno de las refundiciones y la impunidad con que autores y gobernantes se veían con derecho a manipular las obras de otros, hay que recordar que en la consideración general de la época apenas existía una conciencia del derecho de autor y que el acercamiento a estas obras literarias se hacía más desde un prejuicio de carácter moral que desde una consideración estética. Desde este punto de vista, cualquier manipulación dirigida a lograr el beneficio ideológico era bienvenida y no suponía un delito o un atentado contra la integridad de la obra artística, pues se estaba trabajando en un proyecto que tanto tenía una dimensión de futuro como de pasado: tanto se utilizaba la obra de teatro para proponer un modelo de conducta, como para reinterpretar el patrimonio e insertarlo en la nueva cultura nacional.

Si este fue el criterio de los refundidores durante los últimos decenios del siglo y durante parte del XIX, Sebastián y Latre fue uno de los que más lejos llegó en sus correcciones, hasta el punto de negar el modelo, como señala Vellón Lahoz. En sus manos, la «tragicomedia» de Rojas Zorrilla, al mezclar lo cómico con lo serio, desaparece, convertida en estricta tragedia que, entre otras cosas, se ajusta al endecasílabo para perder su polimetría originaria ${ }^{16}$.

13 «La segunda [razón] es la muerte violenta de Tereo ejecutada por Filomena y Progne, sin tener esta aquellos debidos sentimientos de ternura y veneración por su esposo y su soberano, cuyos abominables ejemplos es justo borrar de la memoria de los hombres, procurando inspirarles siempre las estrechas obligaciones del amor y fidelidad con que nace todo vasallo para con sus reyes, aun cuando aquel sea de la mayor elevación», Ensayo sobre el teatro español, cit., s. p.

${ }^{14}$ Parte de un proyecto mayor que incluye «quitar de nuestro teatro tantas comedias semejantes a éstas de Rojas y de Moreto», Ensayo sobre el teatro español, cit., s.p.

15 Joaquín Álvarez BARRIENTOS, «El Quijote de 'Avellaneda' en el siglo XVIII», en El Quijote en el Siglo de las Luces, ed. Enrique Giménez, Universidad de Alicante, 2006, pp. 13-41.

16 Vellón LAHOZ, «El Ensayo sobre el teatro español», cit., p. 171. Por otro lado, si acepta que en los entreactos se representen entremeses, prefiere que no se hagan y 
Como otros refundidores, al fin y al cabo intermediarios culturales, lo que Sebastián y Latre hace es reescribir la obra desde un determinado punto de vista, desde una concreta forma de recepción, que, en este caso, se ajusta a los postulados políticos y cívicos de la España ilustrada de los tiempos de Carlos III y el conde de Aranda, en los que una nueva sensibilidad, guiada por la razón, quiere dirigir al mundo. El hombre de bien, el ciudadano católico, la conciencia del «buen gusto» (ético y estético), la utilidad como virtud en el sentido latino están detrás de las manipulaciones del Cronista de Zaragoza, y también la relectura del pasado nacional, de la antigüedad, como él mismo señala en su dedicatoria al Conde. Todo el trabajo, todo su empeño porque «el celo y amor de buen patriota me obligaron a que emprendiese» esos trabajos literarios, con la mira puesta en conseguir desde el teatro «buenos cristianos, fieles vasallos del rey, hombres útiles al estado y celosos ciudadanos por el bien de la patria» ${ }^{17}$.

Al prólogo del refundidor le siguen dos cartas, una de Fray Onofre Andrés de Asso y otra de Antonio Fortea, abogado de los Reales Consejos, que no aportan nada salvo los tópicos habituales y elogian el trabajo y el empeño reformador y patriota de Sebastián y Latre. La del primero tiene la curiosidad de calificar el trabajo de «pieza de estado», igual que $E l$ sitio de Cales, dedicada a Luis XV, que también fue «pieza de estado».

El trabajo de Tomás Sebastián y Latre no quedó en el olvido. Ya se dijo que Pablo de Olavide lo conoció porque el mismo autor se lo mandó y ambos mantuvieron una breve correspondencia epistolar reproducida por Aguilar Piñal en su libro sobre Sevilla y el teatro del siglo XVIII. Momento importante en la recepción y enjuiciamiento de su refundición, y de las refundiciones en general, fue cuando en 1789 Juan Sempere y Guarinos publicó el quinto tomo de su Ensayo de una biblioteca española de los mejores escritores del siglo XVIII ${ }^{18}$. Que el zaragozano aparezca como uno de los «mejores escritores», teniendo tan magra y poco significativa producción, ya es indicativo de la sintonía reformista que existió entre él y el proyecto gubernamental, del que Sempere fue pieza importante. Es claro que éste le valora desde la utilidad y cercanía a los planteamientos culturales, económicos, publicitarios e intelectuales de la Ilustración. Y es así

que en su lugar, mientras descansan los actores, se interprete alguna música acorde al cariz de la obra representada. Hace otras consideraciones sobre el modo de actuar y sobre los actores, además de proponer algunas medidas para apoyar la escritura de comedias ajustadas al buen gusto. De hecho, en esa línea de colaborar en la reforma, envió su Ensayo a Pablo de Olavide, que se encontraba en Sevilla y tenía una compañía de cómicos que intentaban representar según los modos de la reforma. Francisco Aguilar Piñal, Sevilla y el teatro en el siglo XVIII, Oviedo, Universidad, 1974, pp. 89-90.

${ }^{17}$ Las limitaciones de espacio me impiden estudiar los lazos ideológicos e intencionales que unen a este trabajo con el realizado en 1766 sobre el motín de Esquilache en Zaragoza.

${ }_{18}$ Madrid, Imprenta Real, 1789, pp. 119-126. 
como el proyecto de Tomás Sebastián puede tener cabida en ese Ensayo, que, además de un buen instrumento de trabajo, es un excelente ejemplo de propaganda ilustrada, una muestra de cómo se quiso, y en parte se consiguió, cambiar el panorama español.

Aquí «el señor Sebastián» ha hecho «de una malísima comedia» en la que las dos hermanas matan al rey y donde «no hay unidades, costumbres, caracteres, ni estilo», una buena tragedia. La valoración de Sempere encaja en lo repetido ya: es una labor de patriotismo acabar con tales monstruosidades, su trabajo está bien realizado, pero se presenta una variante respecto de la opinión general, pues, aceptando su buen hacer y la posibilidad de tener éxito sobre los públicos, piensa que no es ese el mejor método para mejorar el «teatro nacional». Se apoya en Pietro Napoli-Signorelli, que había hablado encomiásticamente de esa refundición pero había hecho una objeción de conjunto al método ${ }^{19}$. El argumento de Sempere, que da más importancia a las obras originales, va más allá, pues se sitúa en el debate sobre el valor de los antiguos frente a los modernos, por los que se inclina (igual que Sebastián y Latre a la postre), ofreciendo además un ejemplo, que desdeña, de recepción y sumisión al patrimonio histórico:

El proyecto de corregir nuestras malísimas comedias es efecto de la esclavitud literaria con que muchos miran las obras de nuestros mayores, solo porque nacieron antes; y del injurioso concepto de la edad presente, en la cual se cree falsamente que no hay ingenios tan vastos y extraordinarios como los que admiran, sin fundamento, en las pasadas. Quien se ocupe en corregir nuestro teatro antiguo, tendrá acaso más dificultades que vencer que si trabajara sobre asuntos nuevos, y carecerá de la gloria de ser original ${ }^{20}$.

Esta era, sin embargo, una opinión minoritaria y los públicos continuarían viendo las obras del teatro clásico español en adaptaciones y refundiciones que siempre, en mayor o menor medida, traicionaban al original. Y esto sucedió también con piezas de Rojas Zorrilla, algunas de las cuales tuvieron mucho éxito entre el siglo XVIII y el XIX, por destacar en lo que se llamó «comedia de figurón». Es el caso de Entre bobos anda el juego, cuyo personaje don Lucas del Cigarral se convirtió en referente de este tipo de teatro, al igual que el dómine Lucas de José de Cañizares. Junto a esta se representaron otras que hacían la crítica de «tipos» y desde luego de la figura del «montañés». El éxito de Rojas en los escenarios seguramente haya que achacarlo a su tendencia tremendista, que a veces recuerda ciertos momentos de exageración shakespeariana, y al papel que a menudo tienen las mujeres. Sin pretender hacerle pasar por un feminista, como algún crítico

${ }^{19}$ En Storia critica de' teatri antichi e moderni, Napoli, Vincenzo Orsino, 17871790, 6 vols. La referencia en el lib. 3, cap. 6. Esta historia acumula muchos errores, que fueron puestos de manifiesto por diversos historiadores; entre ellos García de la Huerta que, además, tenía «motivos personales» para atacar a Napoli-Signorelli.

${ }^{20}$ Ensayo de una biblioteca, cit., V, p. 126. 
ha sugerido, con frecuencia son ellas las vengadoras de su honor, como en Progne y Filomena, mientras gran parte de su producción las tiene como protagonistas, lo cual en momentos como el siglo XVIII, de cambio y cuestionamiento del papel de las mujeres, había de tener su adecuada recepción.

\section{Francisco DE Rojas ZorRILla y LEANDro FERnÁNDEZ DE MoRatín}

Cuando Moratín estrenó el 24 de enero de 1806 El sí de las niñas diversas voces surgieron criticando la pieza. Destacaban que no era original el autor, que se había «inspirado» en otras producciones. Los críticos aludieron a L'oui des convents, a Le traité nul de Marsollier, a L'école des mères de Miravaux, a obras de Molière y, ya en el siglo XX, a Entre bobos anda el juego, que tiene, en efecto, bastantes similitudes argumentales. Fue Federico Ruiz Morcuende quien aludió a esa comedia en 1924, al editar las piezas más importantes de Moratín. Él mismo había editado a Rojas Zorrilla unos años antes, en 1917:

El tema del libre albedrío de la mujer para elegir esposo, fue desarrollado por Rojas Zorrilla en su comedia Entre bobos anda el juego. Más complicada y llena de incidentes cómicos ésta que El sí, algunos de los personajes y situaciones son análogos; don Diego, aunque mucho más sensato y menos ridículo, se parece a don Lucas; doña Isabel de Peralta a doña Francisca; Andrea a Rita; Calamocha a Cabellera; don Carlos a don Pedro; doña Francisca como doña Isabel, no conoce exactamente la personalidad de su amante; don Carlos, igual que don Pedro, duda y desespera ante su rival; la acción de $E l$ sí es en una posada; los principales incidentes de Entre bobos ocurren asimismo en una posada; solo una calle de Madrid cita Moratín en El sí, en la escena XIV del acto segundo, y es la misma que nombra Rojas en el verso 632 de Entre bobos: la del Lobo, aunque ciertamente parece que don Leandro sentía predilección por la tal calle, pues la saca a relucir también en la escena III del acto primero de La comedia nueva. Mas aun suponiendo que Moratín tuviese presente la comedia de Rojas, ello no amengua en nada el mérito de El sí de las niñas ${ }^{21}$.

Entre una obra y otra hay, como se ve, mucha relación y semejanzas, pero no tiene sentido abordar el estudio de las «fuentes» desde esta perspectiva y sobre todo no tener en cuenta que Rojas y Moratín pertenecen a mundos y cosmovisiones distintos. La sola lectura de las dos obras pone

21 Teatro, ed. Federico Ruiz Morcuende, Madrid, Ediciones de «La Lectura», 1924, pp. 63-64. En reimpresiones posteriores reduce esta enumeración a la sola mención de la comedia de Rojas como posible inspiración. Francisco ROJAS ZORRILlA, Teatro, ed. Federico Ruiz Morcuende, Madrid, Ediciones de «La Lectura», 1917. Se detienen sobre este asunto John Dowling y René Andioc, en Leandro FERnÁndEZ DE MoRATín, La comedia nueva. El sí de las niñas, Madrid, Castalia, 1979, y Jesús Pérez Magallón, en Leandro FERnÁndez DE Moratín, La comedia nueva. El sí de las niñas, estudio preliminar de Fernando Lázaro Carreter, Barcelona, Crítica, 1994, p. 58. 
de manifiesto las distancias, los mundos diferentes, aparte de la importancia significativa de emplear el verso o la prosa como vehículo de expresión. Desde este punto de vista, si se tienen en cuenta esas diferencias, los parecidos adquieren otra dimensión y para lo que sirven es para evidenciar más el cambio ideológico que había entre un autor y otro, entre una época y otra. Por otro lado, la utilización por parte de Moratín de similares escenarios y de una relación estructural y de personajes casi idéntica, pone de relieve su conocimiento de la tradición dramática y las novedades que aporta al renovar esa tradición. Evidencia cómo se puede dar un giro a los componentes de un teatro que se entendía como portador de las «esencias» españolas y, desde ellos, ofrecer una nueva propuesta de civilidad nacional. Otra vez ofrecer un nuevo sentido a una tradición que se reinterpretaba.

A la vista de los parentescos, es desde luego muy posible que Entre bobos anda juego estuviera en la mente de Moratín, al igual que otras obras, y es posible que le sirviera para ordenar el planteamiento de su trabajo. La protagonista se va a casar, por decisión paterna, con el rico y viejo don Lucas, que la espera en una venta de Illescas, donde se reúnen. Sabemos que está enamorada de alguien que le ha salvado la vida, cuya identidad desconoce y que resulta ser primo de don Lucas, de nombre don Pedro y de casi la misma edad que él. Parte del enredo sucede en la posada y de noche, lo que da pie a citas a oscuras, que ocasionan momentos de gran comicidad. Hay otros paralelos, como las conversaciones entre el pretendiente y el padre de la novia para negar las habladurías sobre los amores de Isabel, y el desenlace feliz para los jóvenes, pues, cuando don Lucas se entera de la situación, en venganza, les obliga a casarse, pensando que la pobreza de ambos acabará muy pronto con su amor. Y esta, desde luego, es una diferencia, respecto de Moratín, esencial. Hay semejanzas, pues, pero estas no ocultan las diferencias; el tono es desde luego distinto, aunque el objeto de las dos comedias, en cuanto al papel de los jóvenes en el matrimonio, no sea muy diferente. Pero los argumentos, cómo se desenvuelven los protagonistas, la función del matrimonio, los referentes, todo es distinto. Si se hubiese inspirado en Rojas, Moratín habría hecho una refundición como la de Sebastián y Latre respecto de Progne y Filomena: la habría vuelto del revés.

Por otro lado, aunque se ha hablado de cierta actitud «feminista» de Rojas, lo mismo que de Moratín, recurrir a este tipo de argumentos en los que se explora un triángulo amoroso desigual era frecuente en la literatura barroca, tanto dramática como narrativa, como lo fue también en la literatura dieciochesca. El tema tenía suficiente atractivo como para ponerlo al día en cada momento y contextualizarlo, dado su éxito. Sea como sea, no es imposible que esa y otras obras estuvieran funcionando en el recuerdo de un Moratín buen lector y gran conocedor de la historia teatral, como demuestra numerosas veces y en sus Orígenes del teatro español, pero eso no significa que fuera su «inspiración» o que la plagiara. Muestra, sólo, 
que conocía bien la tradición dramática y que supo renovarla sin escribir contra ella. Y junto a esto, importa apuntar que, tal vez, una de las razones del gran éxito que tuvo la comedia, el mayor del siglo XVIII, fue que el público reconocía, no solo algo que ocurría a su alrededor y que tenía enorme importancia, sino también una tradición teatral con la que se identificaba $^{22}$.

\section{ROJAS ZORRILLA Y LA ERUDICIÓN. EN EL CANON HISTÓRICO}

La presencia del teatro de Rojas Zorrilla en las obras eruditas del siglo XVIII y del XIX responde a los criterios generales que se adoptaron para tratar de la comedia barroca en esas épocas. Los discursos se dividen entre los que rechazaban ese teatro por no ajustarse a las convenciones modernas, ni en lo moral ni en lo estético, y ahí estarían los preceptistas y los seguidores rigurosos del clasicismo; los que lo entendían como la expresión pura del ser nacional, perspectiva que defendían los casticistas; y los que lo historiaron pretendiendo ser ecuánimes al valorar sus virtudes y exponer sus defectos. Hubo historiadores del XVIII que cayeron, sin embargo, en la mera apología, sobre todo tras los ataques de franceses e italianos, y así trabajos importantes de Lampillas, Serrano y otros no tienen el valor ni la trascendencia que hubieran podido tener, cegados por esta perspectiva.

Gran parte de la actividad erudita y publicística alrededor del teatro se realiza influida por el debate que se origina en el siglo y permanece aún en el XIX, sobre el valor del teatro barroco y de la cultura española. Frente a los ataques de los clasicistas más estrictos (que luego en las décadas finales se suavizan, con figuras como Moratín y Estala), están las defensas de los casticistas más enconados, como la que hace Nifo en La nación española defendida de los insultos del Pensador y sus secuaces, que halla más perfectas, originales y dignas de estimación las piezas cómicas de España que las extranjeras, y que no acepta que llamen «bárbaros a los españoles, porque gustaban de las comedias inimitables de Lope de Vega, Calderón, Rojas, Moreto, Molina, Diamante, Candamo y otros muchos» ${ }^{23}$.

En el siglo XIX, sobre todo en las primeras décadas, sin perder este elemento de beligerancia y defensa, el planteamiento fue otro. Por un lado,

${ }^{22}$ Maria Grazia Profeti, en su edición de Entre bobos anda el juego, Barcelona, Crítica, 1998, p. LVI, escribe a este respecto que Rojas «apunta hacia la falsa apariencia, dibujando un mundo donde nadie está completamente libre de defectos [...]. Moratín, en conformidad con la forma del mundo de su tiempo, preocupado por la enseñanza y la moralidad de las costumbres, nos ofrece un mensaje didáctico, claramente legible».

${ }^{23}$ El título continúa: En este escrito se manifiesta con testimonios franceses que las comedias de España, además de originales, son las mejores de Europa, y que los famosos poetas españoles saben ser celebrados pero no reprendidos, Madrid, Gabriel Ramírez, 1764, pp. 13-14. 
los historiadores y antólogos dieron a conocer el acerbo teatral y tuvieron por lo general una preocupación nacionalista, que dio continuidad a la línea casticista y, en cierto modo, patriótica de identificación del ser español con el teatro antiguo. De esta forma, muchos fueron los que identificaron y calificaron al teatro barroco de teatro romántico, con Agustín Durán a la cabeza ${ }^{24}$. Para ese momento, años treinta, y después, el teatro clásico español era un valor consolidado y sólo se discutía la preeminencia de unos autores sobre otros, mientras los eruditos se dedicaron a estudiarlo y a publicarlo en colecciones que lo hacían asequible al público general y a los interesados de otros países. La intención patriótica, conocida desde el siglo XVIII, estaba también presente en estos hombres del XIX que aún tuvieron que luchar contra los tópicos, los errores y las maledicencias de los extranjeros que escribían sobre España, además de emplear a estos poetas y dramaturgos en el empeño de consolidar el Estado-Nación y los símbolos en los que reconocerse.

En este planteamiento, la figura de Rojas Zorrilla no tiene un especial protagonismo, más allá de lo señalado con relación a las refundiciones y al posible papel en la creación de El sí de las niñas. Su «gran momento» llega en 1827, cuando se publica el primer tomo de sus comedias escogidas, como se verá después. Entre tanto, su presencia en los textos suele ser la de un nombre que acompaña a los destacados autores del Barroco: después de Lope y Calderón, Moreto, Solís y Rojas.

Ignacio de Luzán dedica muchas páginas al teatro en su Poética, que en algunos momentos es una historia literaria desde la óptica clasicista. De Rojas dice: «Don Francisco de Rojas se parecía mucho a Moreto, y no sé si diga que su locución es más dulce, se entiende en las comedias de capa y espada y en las de Abre el ojo y Entre bobos anda el juego, que podemos llamar de carácter, pues en las heroicas, queriendo parecer sublime, delira», y después comenta que se quejaba de las manipulaciones y supresiones a que sometían sus obras los editores, señalando que, en realidad, le favorecían, pues, al quitarle los despropósitos y desvaríos de su pluma, le mejoraban la comedia ${ }^{25}$.

Con matices leves ésta fue la opinión de los clasicistas más estrictos. Frente a los ataques que a la escena española hicieron Du Perron, Linguet y otros, escribieron Blas Antonio Nasarre en 1749 y Agustín de Montiano y Luyando en 1750. En ese debate sobre si España tenía o no teatro arreglado, Rojas tuvo cierto papel, pues tanto uno como otro en sus trabajos sobre la comedia y la tragedia aludieron a su producción, a veces sin nom-

${ }^{24}$ Para esta cuestión, véase la síntesis de Leonardo ROMERO TOBAR, Panorama crítico del Romanticismo español, Madrid, Castalia, 1994.

25 Ignacio DE LuZÁn, La Poética, ed. Russell P. Sebold, Barcelona, Labor, 1977, pp. 405-406. 
brarla, como ejemplo de cierta regularidad. Se refieren a él, pero también a Moreto, a Solís, a Pérez de Oliva, Guillén de Castro, etc. ${ }^{26}$

Nasarre había pensado ofrecer al público esas obras de nuestro teatro para que se pudieran juzgar con criterio, pero no pudo llevar a cabo su proyecto. Los interesados tuvieron que esperar hasta 1785, cuando Vicente García de la Huerta publicó los dieciséis tomos de su antología titulada Theatro Hespañol ${ }^{27}$. En ella, con criterio que le fue discutido, aparecen las obras de los comediógrafos españoles sin retoques, procurando usar buenas copias, aunque los resultados no siempre sean los mejores. Su intención era desde luego, una vez más, patriótica, al dar a conocer ese acerbo criticado por los reformistas y por los extranjeros (franceses e italianos), y su pasión le hizo caer a veces en la apologética, defecto compartido por entonces por muchos de los que quisieron defender y ponderar la cultura española frente a los ataques que recibía del exterior ${ }^{28}$. Es momento, con la pregunta famosa de Masson de Morvilliers, de interrogarse por el carácter de la cultura española y por su valor frente a las de aquellos que quieren desprestigiar a la nación en un episodio más de la larga leyenda negra; es un momento de inflexión en la construcción de los símbolos que acabarían identificando a la nación. El ataque de los eruditos extranjeros sirvió para repensar, revalorizar e historiar el propio pasado, en un proceso que también incluía la reflexión sobre la propia identidad (en el que el teatro tuvo un papel fundamental pues muchos lo entendían como un símbolo de lo español) y sobre el prestigio que la cultura podía proporcionar a los reinos. El enfrentamiento entre países no solo se daba en el campo político y económico: el valor de la cultura también les oponía.

Vicente García de la Huerta, al editar su antología de piezas largas y breves de los siglos XVII y XVIII, se apartó del criterio clasicista y prefirió el acercamiento de carácter histórico, presentando las obras tal cual se habían compuesto. Respetaba así el valor del patrimonio y, frente a un criterio estético de valoración, apostaba por el sentido diacrónico, lo cual no quiere decir que olvidara que, en efecto, unas obras estaban más desarregladas que otras. Al contrario, lo indica, pero le interesa destacar lo positivo, sus valores poéticos e inventivos, la condición de «potencia» que España tenía en ese aspecto y cómo había sido copiada por muchos dra-

${ }^{26}$ Blas ANTONio NASARRE, «Disertación o prólogo sobre las comedias de España», en Comedias y entremeses de Miguel de Cervantes, Madrid, 1749 (Hay edición moderna del prólogo, a cargo de Jesús Cañas Murillo, Cáceres, Universidad, 1992). Agustín DE Montiano y Luyando, Discurso sobre las tragedias españolas, Madrid, José de Orga, 1750; Discurso II sobre las tragedias españolas, Madrid, José de Orga, 1753.

7 Madrid, Imprenta Real, 1785.

28 Theatro Hespañol, cit., I: «espero que la nación, en cuyo obsequio he trabajado [...], recibirá ésta como un testimonio nuevo de mi afecto y de mi verdadero patriotismo» (p. CCVI). 
maturgos, más que ponderar el ajuste a unas normas que no siempre funcionan. Su objetivo era «la vindicación de nuestro teatro, considerado en los términos mismos en que ha sufrido las invectivas y calumnias de los que han tenido la desgracia de no conocerle» ${ }^{29}$. De Rojas, incluye Entre bobos anda el juego, Donde hay agravios no hay celos y otras, además de apuntar un problema desarrollado después: la existencia de dos Franciscos de Rojas, el segundo «Procurador de Toledo» ${ }^{30}$. En la «Advertencia» a la primera comedia, tras recuperar sus quejas sobre el maltrato de los impresores, que relaciona con las de Lope y Calderón, hace una valoración muy positiva: «Su ingenio es uno de los que darán siempre lustre a nuestra nación. La cultura y facilidad de su estilo, y la dulzura de su poesía son comparables a los de aquellos que ocupan el primer lugar de nuestro Parnaso» ${ }^{31}$.

Estas valoraciones de García de la Huerta fueron retomadas por los eruditos del siglo XIX, como se verá a continuación. Por otro lado, Juan Andrés, García Villanueva y otros historiadores del teatro y de la literatura española iniciaban en los años ochenta la redacción de los primeros trabajos que como tales historias pueden ser denominados, que sientan las bases de las del siglo XIX. En ellas, la consideración del teatro clásico español se mueve entre el juicio clasicista que destaca sus defectos por no ajustarse a las reglas, y la valoración positiva de unas obras que influyeron de modo notable en la historia del teatro europeo y que, además, tienen unos valores evidentes ${ }^{32}$.

Las obras de Rojas Zorrilla fueron objeto de atención erudita y se recopilaron ya en el siglo XIX junto a las de otros miembros del Parnaso español, y formaron parte del canon nacional que, para esas primeras décadas, ya está consolidado ${ }^{33}$. La primera selección es la de El teatro español o Colección de dramas escogidos de Lope de Vega, Calderón de la Barca, Moreto, Rojas, Solís, Moratín y otros célebres escritores, precedida de una breve noticia de la escena española y de los autores que la han ilustrado,

${ }^{29}$ Theatro Hespañol, cit., I, p. CXCVIII.

${ }^{30}$ Theatro Hespañol. Catálogo alfabético..., Madrid, Imprenta Real, 1785, p. 253.

31 Theatro Hespañol, II, Madrid, Imprenta Real, 1785, p. 3.

32 Para las historias literarias del XVIII, Inmaculada URZAINQUI, «El concepto de 'Historia literaria' en el siglo XVIII», en Homenaje a Álvaro Galmés de Fuentes, III, Oviedo/ Madrid, Universidad/ Gredos, 1987, pp. 565-589; José Antonio VALERO, «Una disciplina frustrada: la historia literaria dieciochesca», Hispanic Review, 64 (1996), pp. 171-197; Joaquín ÁlvAREZ BARRIENTOS, «Orígenes de la historia literaria», en Historia de la literatura española. 6. Siglo XVIII, coord. Guillermo Carnero, Madrid, EspasaCalpe, 1995, pp. 108-123. Y José CEBRIÁN GARCíA, «Historia literaria», en Historia literaria de España en el siglo XVIII, ed. Francisco Aguilar Piñal, Madrid, Trotta/ CSIC, 1996, pp. 513-592.

${ }^{33}$ Rosa M. ${ }^{\text {a }}$ ARAdRA, «El canon en la literatura española (siglos XVIII y XIX)», en José M. ${ }^{a}$ Yvancos Pozuelo y Rosa M. ${ }^{a}$ ARADRA, Teoría del canon y literatura española, Madrid, Cátedra, 2000, pp. 142-301; RODRÍGUEZ SÁNCHEZ DE LEÓN, La crítica dramática en España, cit., pp. 77-223. 
iniciada en $1817^{34}$. Está publicada en Londres y la selección de dramaturgos ya da cuenta de cuál es el canon el momento. Moratín, olvidados «afrancesamientos», a la misma altura de Calderón y Lope, pero también de Rojas. Para ser fecha tan temprana interesa destacar que la amplitud del criterio del antólogo, que une a unos y a otros, no podría haberse manifestado en España, y sí en la tierra del exilio que era Londres. El autor de la selección y de la introducción, «A. A.», Ángel Anaya, que remite para más informaciones a la antología de García de la Huerta y que usa sus juicios, traza un panorama sintético de la historia dramática y de la escena españolas, y aporta algunas breves semblanzas de los autores ${ }^{35}$. La de Rojas, no puede ser más decepcionante, pues se limita a copiar parte de lo que de él escribió Luzán en su Poética (lib. III, cap. 1), y ya se ha visto: «Don Francisco de Rojas se parecía mucho a Moreto, y no sé si diga que su locución es más dulce, se entiende en las comedias de capa y espada y en las de Abre el ojo y Entre bobos anda el juego, que podemos llamar de carácter, pues en las heroicas, queriendo parecer sublime, delira» ${ }^{36}$.

Sin embargo de trazar, aunque escueto, el juicio de Rojas, en los cuatro volúmenes de que consta esta colección no se encuentra ninguna comedia suya, pero tampoco de Moreto y Solís. No he podido ver más juego que el que guarda la Biblioteca Nacional de España, y en él, al pasar del tercer tomo, con comedias de Calderón, al cuarto, con piezas de Moratín, hay un cambio en la portadilla que puede explicar lo sucedido. La de éste incluye la mención de «Teatro moderno» y la indicación de que es el «Segundo volumen». Según esto, debería de haber al menos un tomo o dos más con las comedias de los dramaturgos del Barroco que faltan y con las relativas al primero del «Teatro moderno», o el proyecto quedó truncado de este modo ${ }^{37}$.

En cualquier caso, esta colección publicada en Londres por Ángel Anaya es un ejemplo de cómo se difundía la cultura española fuera de España y, más en concreto en Inglaterra, en un momento de gran aceptación de nuestra literatura, debido al trabajo que realizaron muchos de los «emigrados».

La segunda selección es la titulada Colección general de comedias escogidas de los mejores poetas dramáticos españoles, iniciada en la imprenta de Ortega en 1826, bajo la dirección de Agustín Durán, Pedro de Gorostiza

${ }^{34}$ Londres, impreso por Jorge Smallfield, 1817-1820, 4 vols. Los otros por diferentes impresores; todos se vendían en la casa Boosey e hijos.

35 Edward Allison PEERS, Historia del movimiento romántico español, I, Madrid, Gredos, 1973, p. 234, da el nombre del compilador, que en la antología solo figura con las dos iniciales.

${ }^{36}$ El teatro español, cit., I, p. XVII.

${ }^{37}$ En los tomos que he visto, el primero lleva la introducción y comedias de Cervantes y Lope; el segundo y el tercero, las de Calderón, y el cuarto, las de Moratín. Allison PEERS, Op.cit., no da información que aclare este respecto. 
y Cepeda, y García Suelto, y es la realmente importante para Rojas, pues dos tomos con una selección de las suyas aparecieron en ella en 1827 y $1831^{38}$. En el primero se incluyeron Del rey abajo ninguno, García del Castañar; Donde hay agravio no hay celos, Entre bobos anda el juego y Don Diego de noche, con sus correspondientes «exámenes», que eran comentarios a las comedias. Por ejemplo, de García del Castañar se comenta que se encuentra en casi todas las casas y que ni es tragedia, ni tragicomedia, ni tragedia urbana, ni drama ni melodrama. Simplemente es «obra divina». En el segundo se incluyen Lo que son mujeres y Abrir el ojo ${ }^{39}$.

A estas colecciones, que erigían «un monumento a la gloria de nuestra patria», se fueron incorporando otras, con mayor o menor fortuna, pero evidenciando ya que había un público que las recibía bien y que se quería combatir las opiniones negativas de extranjeros y de nacionales que, en realidad, no conocían ese acerbo. Es la razón que llevó a Agustín Durán a proponer una Talía española o Colección de dramas del antiguo teatro español, en 1834, con la que quería repetir el éxito obtenido con el Romancero vulgar y seguramente con la anterior colección, pero también contribuir a que sus compatriotas y los críticos tuvieran a su alcance las obras del teatro español, para así poder opinar con fundamento, además de proporcionar a los actores versiones correctas para ser representado. El proyecto, a pesar de ser bien recibido, no pasó del primer tomo, con obras de Tirso: ni los setecientos cincuenta suscriptores ni la ayuda oficial fueron suficientes. Como otros, consideraba en el «Prospecto» que el teatro español acababa con Zamora y Cañizares. Por su parte, Rojas Zorrilla formaba parte de la época que «constituye propiamente la de la originalidad del teatro español» ${ }^{40}$. Esa que acabaría con dos autores que, aunque salen de la herencia calderoniana, reformaron la tradición para adaptarla a los nuevos tiempos ${ }^{41}$.

${ }^{38}$ Comedias escogidas de Francisco de Rojas Zorrilla, Madrid, Imprenta de Ortega y Cia., 1827; Madrid, Ortega, 1831. Sobre esta colección, Leonardo ROMERO TOBAR, «La Colección general de comedias de Ortega (Madrid, 1826-1834)», en Varia bibliographica. Homenaje a José Simón Díaz, Madrid, CSIC, 1988, pp. 599-610, quien piensa que el Gorostiza que participó es el señalado, y no el más famoso, que por entonces se encontraba en México. Este Pedro de Gorostiza arregló la comedia de Rojas Lo que son mujeres, según la Gaceta de Madrid de 17 de julio de 1831.

39 Esta última comedia aparece con ese título, «Abrir» y no «Abre», en bastantes textos del siglo XIX.

40 «Prospecto», sin datos, pero Madrid, Aguado, 1834, s.p.

${ }^{41}$ Hubo otras muchas colecciones pero su aportación no es significativa, o publicaron poemas, novelas, romances o teatro anterior a Lope. En 1846, D. C. SCHÜTZ recogió el Teatro español. Colección escogida de las mejores comedias castellanas desde Cervantes hasta nuestros días, Bielfeld, Lib. de Velhayen y Klasin. En 1854 el Eco Hispano-Americano publicó una Colección selecta del antiguo teatro español (Paris, Imp. de Thunot y Cia.) y en ella incluía García del Castañar. Antes, José Marchena, Pablo Mendíbil y Manuel Silvela publicaron sus bibliotecas y antologías generales. 
La presencia de obras de Rojas en las colecciones y las selecciones de sus comedias responde a la consideración positiva que transmitían los tratados de erudición publicados por entonces. Su presencia en ellos es ya algo natural, que no se cuestiona, aunque se discutan sus valores. Martínez de la Rosa en 1827, Eugenio de Ochoa en su Tesoro del teatro español, Lista en sus lecciones del Ateneo, Gil de Zárate en su Manual de Literatura, entre otros, hacen aportaciones a la valoración del autor, lo mismo que algunas de las más importantes figuras extranjeras, como Ticknor en su historia de la literatura y el barón de Schack, en Geschichte der dramatischen Literatur und Kunst in Spanien, de 1854. Martínez de la Rosa está cerca de las opiniones de Luzán sobre sus desvaríos, delirios y gongorismo, pero valora su sentido de lo cómico, su capacidad para expresar cuadros de costumbres, sus agudezas y donaires, además de otros aspectos de su producción ${ }^{42}$.

Alberto Lista dedicó una de sus clases en el Ateneo al poeta. En ella le llama el primer trágico español y destaca, sin que sea un defecto, que mezcla lo cómico con lo trágico, sus buenos argumentos, las «situaciones terribles y catástrofes bien graduadas», mientras considera, mostrando el paso del tiempo, que el personaje de García del Castañar es el «tipo ideal de la antigua virtud y del antiguo honor de los españoles», personaje que se apropió Máiquez y expresó magistralmente ${ }^{43}$. Su opinión se inserta en el debate sobre si el teatro antiguo expresaba o no el carácter nacional y por ella se constata su convencimiento de que el español moderno no tenía que ver con «el tipo ideal» antiguo. En 1844 se habían recogido sus artículos publicados en el periódico El Censor y en uno de ellos, sobre el teatro español, rechazaba la opinión contraria y ejemplificaba con la comedia de de García del Castañar y con su conducta hasta qué punto el teatro de los Siglos de Oro era expresión de las costumbres antiguas (no de las modernas) y no una creación ideal de los poetas:

García del Castañar no pertenece a un mundo ideal creado por Rojas. Sufre la injuria de don Mendo, porque cree que es el rey: apenas sabe que no lo es, le atraviesa el corazón. Lo hubiese hecho en iguales circunstancias cualquier caballero de la corte de Felipe $\mathrm{IV}^{44}$.

${ }^{42}$ Francisco MARTínEZ DE LA ROSA, «Apéndice sobre la comedia», en Obras literarias, II, París, Julio Didot, 1827, pp. 447-449. Han estudiado la Poética de este autor, José Cebrián García, «Significación y alcance de la Poética de Martínez de la Rosa», Revista de Literatura, 103 (1990), pp. 129-150; Pedro OJEDA ESCUDERO, «Hacia el drama histórico por el justo medio», en AAVV, Cuatro estudios de literatura, Salamanca, Grammalea, 1995, pp. 11-51; Checa Beltrán, Razones del buen gusto, cit., pp. 311-329.

43 Alberto LISTA, Lecciones de literatura española, explicadas en el Ateneo Científico, Literario y Artístico, II, Madrid, José Cuesta, 1853, p. 273.

${ }_{44}$ Alberto Lista, Ensayos literarios y críticos, prólogo de José Joaquín de Mora, II, Madrid, Calvo y Rubio, 1844, p. 68. 
A pesar de algunas voces críticas, la interpretación nacionalista del teatro clásico español había penetrado en la historiografía y desde entonces pasaría a formar parte de los libros de texto, como se ve en el Manual de literatura de Antonio Gil de Zarate, en el que hace además una valoración muy positiva del autor, aludiendo a su feliz inventiva, a su estilo claro, a pesar de la «retumbancia», etc. ${ }^{45}$ Seguramente aquí se hace eco de unas palabras de Eugenio de Ochoa, en el Tesoro del teatro español, de 1840, donde había declarado paladinamente que Rojas, además de figurar en «primera línea entre nuestros escritores dramáticos» y haber brillado en ambos géneros, «es uno de los grandes maestros de la lengua». En el comentario detallado de García del Castañar informa de que era tan conocida en España «que apenas hay joven medianamente educado que no recite de memoria algunos trozos de ella» ${ }^{46}$. Ochoa se muestra decidido admirador del autor, lo mismo que Gil de Zárate, que hace un extenso comentario de esa misma comedia.

No son pocos los testimonios que aluden al gusto y aceptación de la obra sobre García del Castañar, y también son importantes los que relacionan su apreciación con Isidoro Máiquez, que la adoptó y la representó numerosas veces, siempre con éxito. Lista acaba de reconocerlo así; en 1826, en el examen que se hace de ella en la colección de Comedias escogidas, se dice que «era una de las piezas favoritas de Máiquez. Sus tradiciones se conservan en el teatro. Si Rojas se la hubiera visto representar, hubiese estimado en mucho más su obra» ${ }^{47}$. Mesonero Romanos, que alude varias veces a ambos en sus Memorias de un setentón ${ }^{48}$, al editar a Rojas en 1861 lo comenta también y añade que esa predilección se debe al buen hacer de Dionisio Solís, que hubo de ser quien se la dio a conocer al actor. De esta forma, no solo la buena aceptación popular, sino también la positiva valoración de los eruditos se deberían al buen trabajo de recuperación e interpretación que habrían hecho a comienzos del siglo XIX el refundidor y hombre de teatro que era Solís y el gran actor que fue Máiquez ${ }^{49}$.

45 Antonio GIL DE ZÁRATE, Manual de literatura. Segunda Parte. Resumen histórico de la literatura española, Madrid, Boix editor, 1844, pp. 357-377. Véase Miguel RAmOS CORRADA, La formación del concepto de historia de la literatura nacional española. Las aportaciones de Pedro J. Pidal y Antonio Gil de Zárate, Oviedo, Universidad, 2000.

${ }^{46}$ Eugenio DE OCHOA, Tesoro del teatro español desde su origen (año de 1356) hasta nuestros días, IV, Paris, Garnier hermanos, 1898, pp. 338 y 339. Incluye García del Castañar, Donde hay agravios no hay celos y Entre bobos anda el juego, que parecen formar la «representación canónica» del autor.

${ }^{47}$ Comedias escogidas, cit., I, p. 110.

48 Ramón DE MESOnero Romanos, Memorias de un setentón, eds. José Escobar y Joaquín Álvarez Barrientos, Madrid, Castalia/Comunidad, 1994.

49 Ramón DE MESONERo Romanos, «Apuntes biográficos, bibliográficos y críticos de don Francisco de Rojas Zorrilla», en Comedias escogidas, cit., p. XIII. Véase también Emilio Cotarelo Mori, Isidoro Máiquez y el teatro de su tiempo, Madrid, José Perales, 1902. 
Mesonero, en su contribución a la «Colección de nuestros insignes dramáticos del siglo XVII», acepta a Rojas entre los grandes y por ello, porque es importante, discute y matiza opiniones. Si lo tiene por uno de los primeros, como ya se ha indicado y como afirma «la crítica moderna», él piensa que es quien llevó más lejos «la indisciplina, el desentono, la degradación, en fin, de su magnífico ingenio» ${ }^{50}$. Y ahí reside, precisamente, la razón del tipo de selección que ha hecho, dejando fuera aquellas obras mitológicas y de santos en las que esas condiciones brillan en demasía. Ya que esa misma crítica moderna valora más sus capacidades para la tragedia que las que poseyó para la comedia, ha incorporado también obras de ese gusto. Sin embargo, él considera que salvo García del Castañar, las demás «tragedias» no se sostienen, y donde realmente brilla el autor es en las comedias de capa y espada y enredo, en las de costumbres y caracteres. Ahí no tiene rival, tras Calderón y Moreto, pues en ellas muestra «su profundo conocimiento de la sociedad», ya que su teatro la expresa y retrata.

La incorporación del autor toledano a la Biblioteca de Autores Españoles, junto a los grandes nombres del teatro español, supuso su consagración como un clásico indiscutible, que pasaba a figurar en el canon dramático, si bien en la segunda fila, tras ocupar Lope y Calderón la primera. En esa posición, junto a Tirso, Moreto y los demás, formaba el grueso de aquellos que fueron utilizados por los franceses para «copiarnos» y luego criticarnos, y por los eruditos del XVIII y XIX para dibujar el carácter nacional, pues sus obras expresaban las esencias patrias.

$\mathrm{Su}$ trayectoria en ese período decisivo para la consolidación de identidades, símbolos e interpretaciones de la historia, no es especialmente relevante, está sumida en los debates sobre la consideración del teatro español en los siglos XVIII y XIX y sobre el modo de aceptar o entender ese pasado. Al mismo tiempo, su inclusión en el canon historiográfico y dramático nacional camina de la mano de la inclusión de los otros dramaturgos considerados de primera fila por ser más brillantes en su exposición del carácter español y por tener más talento. En este sentido, y dado que no era una figura comparable a las de Lope o Calderón, se beneficia de los adelantos que estos hicieron en la apreciación de los críticos. Una vez aceptados, llega el momento de matizar, y es entonces cuando se comienzan a diferenciar sus cualidades como trágico y como cómico; cuando se critican sus excesos verbales o sus escenas tremendas, pero también cuando se pondera su capacidad costumbrista, su buena lengua, sus condiciones para dibujar caracteres y escenas de impacto, además de su filosofía.

Por otro lado, algunas de sus comedias, las canónicas, consiguieron una excepcional consideración entre el público y los críticos, y así Entre bobos

${ }^{50}$ Mesonero Romanos, «Apuntes biográficos, bibliográficos y críticos de don Francisco de Rojas Zorrilla», cit., p. XVIII. 
anda el juego y sobre todo García del Castañar se perfilaron como aquellas que todos estaban de acuerdo en considerar las mejores suyas e incluso, en el caso de la segunda, como una de las que se podía utilizar para apuntar la idea de que el teatro clásico español era expresión de nuestros valores y carácter, en contra de lo que había comentado Sebastián y Latre. La otra, Entre bobos anda el juego, tuvo su protagonismo en tanto que posible «fuente» de El sí de las niñas, si bien la posibilidad se formuló ya en el siglo $\mathrm{XX}$, sin encontrar demasiado eco. Ninguno de los que estudió el teatro clásico y lo editó en el XIX reparó en esa posible similitud (o si lo hizo no consideró necesario destacarlo), a pesar de que algunos eran grandes admiradores y conocedores de ambos autores: ni los encargados de la Colección general de comedias escogidas, ni Ochoa, ni Mesonero Romanos, que admiraba a Moratín y editó a Rojas, señalaron esos parecidos, seguramente porque eran conscientes de que, aunque se daban, las diferencias y los mundos referenciales eran tan distintos que abortaban cualquier comparación.

Por último, Sebastián y Latre rescribió Progne y Filomena para convertirla en vehículo de expresión de las inquietudes de su tiempo, en un intento de corregir las interpretaciones del pasado dando a éste un nuevo sentido que iniciaba un proceso de aceptación y al hacer una nueva lectura de la sociedad y de su literatura. Abría con esta obra de Rojas una nueva manera de tratar y aceptar el teatro clásico y su mundo referencial, que pervivió a lo largo de dos siglos, y que, si por un lado contribuía a dar actualidad a ese tipo de teatro, por otro lo manipulaba tanto que lo convertía en otra cosa: en la expresión de los nuevos intereses didácticos y políticos de los gobiernos ilustrados.

Así pues, el teatro de Rojas Zorrilla conoció los vaivenes críticos e interpretativos propios del teatro antiguo español, en el que destacó como figura relevante, aunque no a la altura de los inalcanzables Lope y Calderón. Junto a ellos, los espectadores, los críticos, los dramaturgos y los eruditos lo elevaron a ese Parnaso nacional que ofrecía figuras y obras de altura capaces de ser enfrentadas sin sonrojo a las de los otros parnasos nacionales. A él y a los demás autores del Siglo de Oro, de los que se pensaba que habían sabido representar las costumbres y crear un teatro nacional, se les ponía como ejemplo para los nuevos comediógrafos, que, en años de crisis, no eran capaces de proponer un teatro similar: que reflejara el nuevo carácter de los españoles, sus costumbres y su idiosincrasia. 